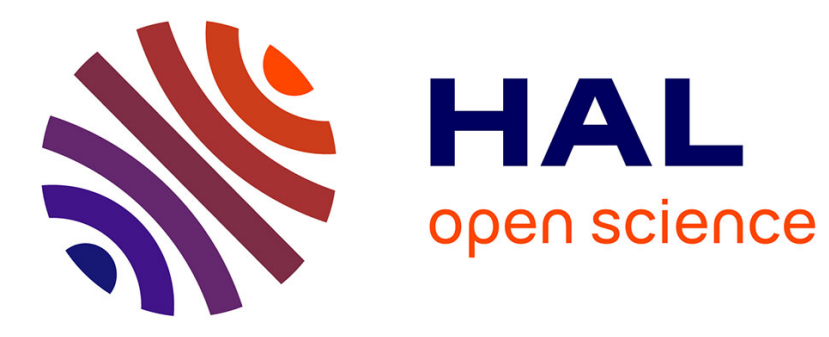

\title{
Heuristics-based Design Process
}

Manuela Calle-Escobar, Ricardo Mejia-Gutierrez, Jean-Pierre Nadeau, Jérôme Pailhes

\section{To cite this version:}

Manuela Calle-Escobar,, Ricardo Mejia-Gutierrez, Jean-Pierre Nadeau, Jérôme Pailhes. Heuristicsbased Design Process. International Journal on Interactive Design and Manufacturing, 2014, pp.1-18. hal-01070213

\section{HAL Id: hal-01070213 https://hal.science/hal-01070213}

Submitted on 14 Oct 2014

HAL is a multi-disciplinary open access archive for the deposit and dissemination of scientific research documents, whether they are published or not. The documents may come from teaching and research institutions in France or abroad, or from public or private research centers.
L'archive ouverte pluridisciplinaire HAL, est destinée au dépôt et à la diffusion de documents scientifiques de niveau recherche, publiés ou non, émanant des établissements d'enseignement et de recherche français ou étrangers, des laboratoires publics ou privés. 


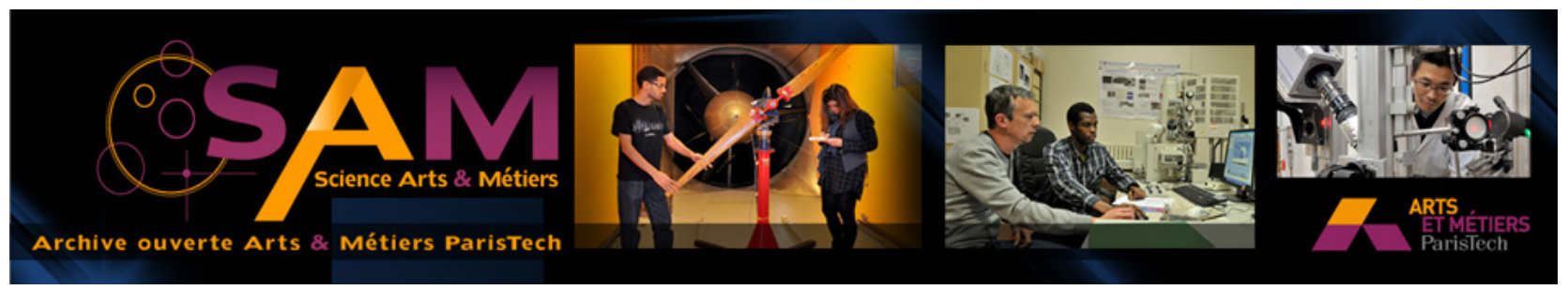

Science Arts \& Métiers (SAM)

is an open access repository that collects the work of Arts et Métiers ParisTech researchers and makes it freely available over the web where possible.

This is an author-deposited version published in: http://sam.ensam.eu

Handle ID: .http://hdl.handle.net/10985/8666

\section{To cite this version :}

Manuela CALLE-ESCOBAR, Ricardo MEJÍA-GUTIÉRREZ, Jean-Pierre NADEAU, Jérôme PAILHES - Heuristics-based Design Process - International Journal on Interactive Design and Manufacturing (IJIDeM) p.1-18 - 2014 


\title{
Heuristics-based Design Process
}

\author{
Manuela Calle-Escobar · Ricardo Mejía-Gutiérrez · Jean-Pierre Nadeau · Jérôme \\ Pailhes
}

\begin{abstract}
This article explores the applicability of heuristic rules into the decision-making processes involved in design practices, with the aim of generating a strategic approach for the fixation, tangibilization and re-utilization of knowledge within organizations. For this purpose, the research focuses on the creation of a methodological approach and a support tool that seeks to facilitate the introduction of heuristics into particular stages of the design process, such as concept development and architecture definition. This is achieved by providing an initial analysis of the design problem, and the definition of specific problem solving actions based on heuristics. This means that, with the aid of tools specifically developed for the method, the process will help design engineers explore several solution principles with applications previously implemented in diverse domains, thus triggering creativity in problem solving activities. This will enable a more diverse concept generation and a more detailed product development process. In addition, it will allow organizations to work with tools and procedures for them to ensure that emerging knowledge can be integrated to the proposed approach and reused in the future.
\end{abstract}

Keywords Heuristics · Design methodology · Decisionmaking $\cdot$ Product Design $\cdot$ Conceptualization

M. Calle-Escobar and R. Mejía-Gutiérrez

Design Engineering Research Group (GRID)

Universidad EAFIT, Cra. 49 N. 7 Sur 50, Medellín, Colombia

E-mail: \{mcallees, rmejiag\}@eafit.edu.co

J.P. Nadeau and J. Pailhes

Arts et Metiers ParisTech, I2M, UMR 5295.

F-33400 Talence, France

E-mail: \{jean-pierre.nadeau, jerome.pailhes\}@ensam.eu

\section{Introduction}

Every design process in general is, in itself, a problem solving process [23]. Specifically, design processes that are oriented towards product development, aim to give tangible technical solutions to situations that demand the creation of artifacts or systems for the satisfaction of certain needs. This particular aspect of design, namely that of intending to solve human needs from a technical perspective, is precisely what defines design practice as a problem solving activity.

The decisions that aim to solve design issues in any particular stage of the process are often of iterative nature [22] and are made under conditions of uncertainty [3]. Ultimately, the choices made end up restraining or altering the possibilities of a design process in terms of technical and conceptual direction. As a matter of fact, it is known that any choice in early stages of the design process has indeed a direct impact in the cost of the product life-cycle, accounting for as much as $80 \%$ of said costs [24], accentuating the importance of well made decisions in early stages of product development.

Therefore, it is common for design engineers to face questions such as: Which of the concepts best embodies the initial requirements? How to solve the technical contradictions that arise from conflicting requirements? Is there a more straightforward way to approach a particular solution?

In environments where design practice is habitual, such as enterprises, $\mathrm{R}+\mathrm{D}$ departments and academic surroundings, it is expected to encounter, whether tangible or not, existing knowledge regarding the most appropriate way to respond to these and other specific questions related to design problems. The answer to such questions is generally based upon praxis and experience that has been obtained by individuals and organizations when giving solutions to similar problems in a systematic manner. However, how can an organization ensure that the answers that are already known 
will be readily available in the future for the resolution of a similar problem?

The problem is precisely rooted in the fact that, when the design outcomes are drawn from practice and a nonstructured process, there is a certain risk that the knowledge generated from practice and experience will not be of use for the organization in the future, because there is no effective or structured way to access it. Consequently, it is important to count with methods and tools that guarantee the permanence of knowledge within organizations, thus allowing its utilization in future occasions. The value of making an effort towards the understanding, consolidation and structuring of knowledge being generated through the execution of design processes, is that it eventually enables the solution of design problems in a more effective way; specifically because counting with methodological strategies that enable the design engineer to consciously employ resources that have been previously used in other situations, will lead design engineers towards attaining new design solutions in a more direct manner.

This is the fundamental purpose of heuristics: to create a structure for the existing knowledge in order to ensure a logical route for its reuse in the future, and obtain optimal results in new problem solving situations [25].

The positive implications of implementing a heuristicsbased approach are reflected not only in the time and cost reduction during project execution, but also in the conceptualization process in itself, given that the usage of heuristic strategies can enhance the diversification of design alternatives and strengthen conceptual exploration.

The purpose of this study is, therefore, to explore how heuristics can be used within design processes and what benefit can be derived from such implementation.

\section{Literature review}

By definition, heuristics refer to the proceedings or approaches that enable someone to reach a solution for a particular problem through the implementation of a "rule of thumb", derived from experience rather than an exhaustive process. It is defined "as an aid to learning, discovery, or problem-solving by experimental and especially trial-and-error methods" [16]

In the design context, they refer to technical or conceptual solutions which implementation has been previously applied and proven in another domain or context, but which can be extrapolated to similar design problems. In this sense, the application of heuristics into design, which is the subject that concerns the present research, offers a particularly interesting view on the design process, due to the fact that it highlights the value of existing knowledge for the solution of problems.
A number of previous works have embarked in the task of offering a structured approach towards the incorporation of heuristics in the product design process.

The first approximations, such as Synectics [10] and SCAMPER [6], emerged from the field of the theory of learning, and were implemented afterwards as creativity tools for design processes. SCAMPER proposes a set of 11 heuristics with the purpose of generating new alternatives from the reconfiguration -architectonic reconfiguration, in the design context - of existing solutions. Synectics, on the other hand, is based upon the use of analogies and metaphors as strategies to enhance creativity, in order to diversify results in the concept generation process.

CBR (Case Based Reasoning) [14] [13], is a reasoning strategy that draws upon previous solutions to explain, interpret or solve current problems. Consequently, the existence of a knowledge base is required as a starting point for problem solving, as well as a series of strategies that enable the adequate recognition and interpretation of the functional element of previous solutions that are applicable to the current problem.

These strategies offer, without a doubt, the possibility of obtaining diversity within creative processes. However, being tools derived from other areas of knowledge, their specificity in the application on design cases is limited, particularly because elements such as the language used are not design-specific.

The work of Yilmaz and other collaborating authors [5] seeks to solve to a certain extent the limitations spotted in the previously exposed tools. His studies, supported in the analysis of case studies with design experts [28], are oriented towards the identification of common strategies related specifically to product design, used during the conceptualization stage. The result of his research is a set of 60 heuristics which, according to his analyses, facilitate the generation and diversification of concepts in practice. However, the heuristic rules proposed by the authors remain generic, and strongly linked to the initial concept generation stage.

Another development of similar nature, but with a stronger orientation towards the solution of technical problems, is TRIZ [1], which along with its methodological implementation -ARIZ [2] — is one of the most widespread tools in the field of design. It is a development built upon an extensive knowledge base, created from the analysis and categorization of a great number of patented technical solutions. The idea behind the implementation of Altshuller's methodology is that, through the application of one or more of the 40 inventive principles available, the design engineer is capable of consolidating a feasible technical solution that solves the design contradiction initially identified. However, an important limitation related to the implementation of this tool is that it requires the identification of the technical problem in terms of a functional contradiction, which is not always eas- 
ily identifiable during conceptualization stages, particularly when the product definition is not yet concrete.

Subsequent developments have been built upon the work of TRIZ, such as Polovinkin's heuristics [21] and de Carvalho's work [27]. Fundamentally, these approaches aim to continue nurturing the extensive knowledge base of TRIZ, as well as explore new possible heuristic rules.

It is also worth noting the work of Stone [26], in which heuristics are proposed for the identification of possible modular configurations during conceptualization. Subsequent applications have been derived from his work [7].

Additionally, the usage of heuristic optimization, with the implementation of strategies such as genetic algorithms [15], particle swarm algorithms [12] and Monte Carlo techniques [11], has led to the development of a whole new field of application for heuristics, particularly in mechanical design [4].

As it can be seen, although previous studies have been carried out in the field of heuristics, its specific approximation to the field of design is still incipient. On the other hand, aspects related to the social, geographical and cultural conditions might have a significant impact in the way design processes are executed in the local context.

Additionally, heuristics as support for decision-making in engineering design, corresponds to the ideal approach to integrate experts, through technical knowledge, in the design process. This concept is linked to the Interactive Design approach, as it considers experts and knowledge modelling as an important factor to offer interactive support to design engineers. Additionally, the evolution in Information and Communication Technologies (ICT) offers interesting approaches to implement reusable knowledge into decisionmaking. Literature in Interactive Design establishes that different disciplines may interact through new developments on the domain of knowledge engineering and through the exploitation of computational tools [9].

Particularly, the integration of heuristics with Interactive Design processes and strategies is a field open for exploration. Interactive design in itself encompasses a series of approaches that deal with numerous design issues related to decision making in the product development process. Specifically, interactive design explores the relationships and methodologies involved in the "virtualization" of particular design practices and activities, such as modelling and representation of design concepts and virtual prototyping, among others. However, Interactive Design also deals with fostering innovation within industrial environments and in particular with the provision of "efficient methodologies for capturing and reusing relevant knowledge" [8].

In this sense, the present work can provide an interesting perspective on how to approach and integrate design processes in preliminary stages to the stages where virtual environments take place, especially by providing a structure for capturing and reusing knowledge, and by detailing a stepby-step methodology that fosters the clarification of design tasks and procedures for an effective preliminary design definition.

\section{Heuristic rules: Development and implementation}

The stage of concept development is remarkably important for the definition of the product architecture, as it has been explained before. Most of the time, problems are generally approached based upon the experience and know-how of design engineers, or arbitrary choices derived from strong personalities within a company, or the history of the company itself.

However, it is crucial not to allow "a priori" choices dictate the meaningful architectural aspects of the product.

Consequently, the establishment of design rules that are supported upon knowledge of numerous actors that together create a common knowledge base can become a way to guide design engineers throughout their choices, through the determination of patterns that can be structured in the shape of problem solving strategies.

Polovinkin, for instance, has proposed a number of rules grouped into nine sections, comprising a total of 121 rules that are derived from innovation principles, resource management, and the multidisciplinary experience of design engineers.

The mentioned rules have a global character, meaning a large spectrum of application, and can be related to heuristics, as being rules that have not been proved (or can not be proven) but which justification leaves no place for doubt.

The nine groups of Polovinkin's rules are:

1. Transformation of shape

2. Transformation of structures

3. Transformation in space

4. Transformation in time

5. Transformation of movements and mechanical actions

6. Transformation of materials

7. Differential resources

8. Quantitative modifications

9. Transformations related to evolutionary trends

Polovinkin's rules have the advantage that they can be implemented without a defined methodological framework. Their application enables the covering of a broad spectrum within the space of possible solutions because of the generic and universal character of the rules. However, there is no formalization of the design problem to solve, which can consequently derive in a somewhat ineffective application of the rules.

This research proposes the utilization of particular heuristics with the purpose of helping design engineers gain a comprehensive vision of any design problem. 


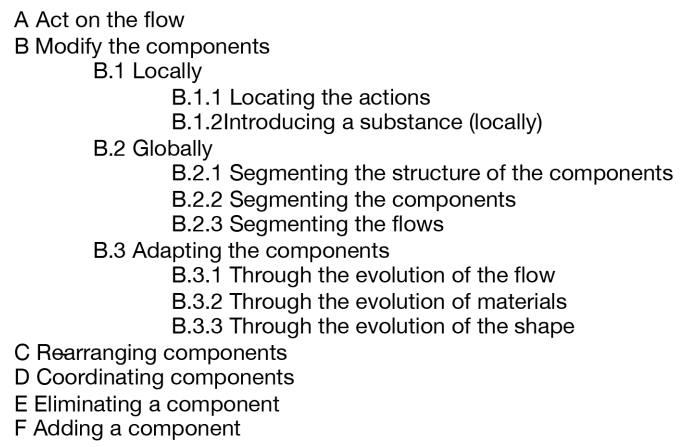

Fig. 1 Excerpt of heuristic rules. Branch B: Modification of components

In general, a heuristic is simple, explicit, practical and easily implemenTable . Heuristics must be, in a sense, "universal", and can be interpreted within different contexts of design. Heuristics represent the translation of an experience, the formalization of the state of the art of the engineer, and the analysis of existing solutions. In fact, the analysis of technical systems show that design engineers use recurrent methods for problem solving.

The purpose of this research is to express said techniques through a set of 78 systematically organized rules. The heuristic rules are expressed in segments of sentences arranged in different levels. These selected segments are chained with additional segments towards the construction of an explicit sentence.

\subsection{Structuring and hierarchization of heuristic rules}

In order to explain the construction of a group of heuristic rules, an excerpt of heuristics related to modification of a component is shown (See Figure 1). The modification of a component can take place at a local or global scale, or through the adaptation of said component. Locally, the design engineer can modify either the actions or the substances that are present within the system.

For a problem linked to the coupling of physical phenomena, the design engineer uses classic decoupling techniques which conduct to the intervention of a widely known principle: the principle of segmentation.

This is why, in the branch B2, the research sets the proposal of successively segmenting the global structure, followed by the components, and up to the internal flows. The adaptation of components will be supported on the evolution of flows, materials and shapes.

The detailed composition of said heuristics has been presented and developed in the thesis presented by Morillon [17], which is based upon Polovinkin's rules, the laws of evolution, the standard solutions, the innovation principles as defined by TRIZ theory, and general engineering knowledge.
These heuristic rules are built up into a hierarchic treelike structure. Fragments of sentences, which level of abstraction decreases along the course of the arborescence, conFigure the structure of 78 rules.

The branched structure also offers the possibility for an initial portion of a rule to unfold into several different strategies, thus enabling the design engineer to explore diverse possible solution principles for a single problem

Each rule is conformed by segments of sentences that grow in level of detail as they escalate throughout the structure of branches. The level of detail corresponds to a hierarchical organization that helps design engineers to identify the kind of approach they want to take on a problem, and determine the sort of solution strategy they wish to implement.

The structure of the heuristics proposed in this study helps design engineers to approach diverse problem solving situations, by gradually determining the typology and location of the redesign efforts. The choices that design engineers face when approaching the heuristic tree will be described in the following subsections.

\subsubsection{Cause-Effect approach}

With the purpose of establishing an approach for the utilization of heuristic rules, a cause-effect vision is proposed. In this vision, any particular design problem is disaggregated into two entities:

- An entity S1, which is the cause of the problem

- An entity S2, the element to be studied, and where the effects of the problem are visible.

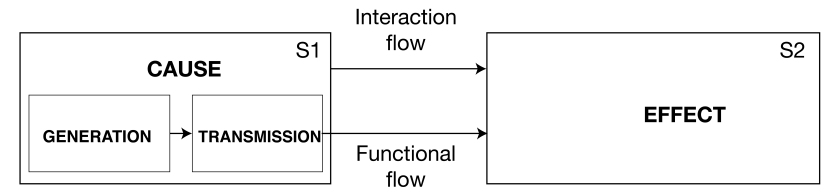

Fig. 2 Cause-effect model

In this approach, the system S1 generates and transmits a functional flow to system S2. Depending on the type of interaction (with or without interaction components, meaning with or without physical contact among both entities), other types of flows, called interaction flows will emerge.

The functional and interaction flows between S1 and S2 will induce effects on the system S2, as shown on Figure 2. It is the analysis of said effects what will enable design engineers to determine whether there is a problem or not within the overall system. 
Table 1 Produced and induced effects

\begin{tabular}{llll}
\hline $\begin{array}{l}\text { State } \\
\text { variables }\end{array}$ & $\begin{array}{l}\text { Time } \\
\text { variables }\end{array}$ & $\begin{array}{l}\text { Produced } \\
\text { effects }\end{array}$ & $\begin{array}{l}\text { Induced } \\
\text { effects }\end{array}$ \\
\hline \multirow{2}{*}{ Force } & Speed & Strain & $\begin{array}{l}\text { Gap/Clamping/ } \\
\text { Stresses/Vibrations }\end{array}$ \\
\cline { 3 - 4 } Pressure & Volume / & Friction & $\begin{array}{l}\text { Wear/Heat transfer/ } \\
\text { Dilation/Retraction /Gap/ } \\
\text { Clamping/Stresses/Creep }\end{array}$ \\
\cline { 3 - 4 } & Flow rate & Friction & $\begin{array}{l}\text { Leaks/Stresses } \\
\text { Dilation/Retraction/ } \\
\text { Gaplamping/Stresses/ } \\
\text { Pollution/Clogging }\end{array}$ \\
\hline & & Heat flow & $\begin{array}{l}\text { Dilation/Retraction/Gap/ } \\
\text { Clamping/Stresses/ } \\
\text { Creep/Icing }\end{array}$ \\
\cline { 3 - 4 } Temperature & Capacity rate & & $\begin{array}{l}\text { Dilation/Retraction/ } \\
\text { Gap/Clamping/Stresses/ } \\
\text { Pollution/Clogging }\end{array}$ \\
\cline { 3 - 4 } & & & Friction
\end{tabular}

The utilization of tools such as the one available in Table 1, for instance, can be of help for classifying and pointing out such effects.

In the Cause-Effect model, every effect has a cause. What is worth noting is that certain effects can be desired and useful in any particular system, but others are not desired and consequently detrimental. Therefore, the problem can come from any of the following configurations:

- A desired effect is insufficient

- A desired effect is not produced

- An undesired effect is produced

As it has been previously stated, the purpose of this research is to come up with a quick problem-solving method and make it available for any engineer without prior training.

This research is articulated around these three different conditions of a design problem. Once the initial situation that poses the problem has been identified, the design engineer can proceed to use the systematic method proposed here, which is composed of different stages.

The first stage involves the definition of the action to undertake. The second stage deals with the selection of the particular zone where said action will take place. And finally, in the third stage, the design engineer must define whether to act upon the different components involved in the conflicting entity, or upon the flow that connects said components.

This structured procedure enables the design engineer to approach the problem, leading down to increasingly precise levels. Thus, the design engineer will be able to choose a branch of heuristics which will lead to an explicit statement that can be later interpreted in context in order to generate solutions.

\subsubsection{Systematic analysis of the possibilities of resolution}

The first question that the heuristic tree challenges design engineers to solve is what kind of specific action is expected to be performed on the problem.

At this point, there are four possible actions to be taken:

- Suppress or eliminate the problem

- Reduce the problem

- Displace the problem

- Exploit the problem

Once the first decision is made, the team can move on to the next stage.

\subsubsection{Systematic analysis of the area of action}

The second step involves the selection of the area of action in the system. This selection is intrinsically bound to the Cause-Effect model. There are five possibilities of action:

- Generation

- Transmission

- Interaction

- Flow

- System

At this point, it is also suggested to evaluate all the available resources for the particular situation at hand.

\subsubsection{Systematic analysis of the ways to act upon the problem}

As it has been mentioned before, heuristics aim to propose a global strategy to act upon a number of problems based on a single expression.

For this purpose, the heuristic rules envisioned in this study have been proposed for design engineers and engineers to implement at this point.

In this sense, the first-level choice is focused on determining the kind of action to execute on the system. In the case exposed in Figure 1, for instance, the design engineer must choose whether to act upon the flow, modify, rearrange, coordinate, eliminate or add components.

The crucial aspect at this point is that the expression of each of the heuristics must be comprehended by a diverse typology of users and must be adaptable to different kinds of systems.

Therefore, the semantic meaning of the expression, and particularly the words and verbs used for the construction of the sentence acquire an important value, given that it must be global enough to encompass as many solution strategies as possible, yet specific enough to successfully guide design engineers to make particular choices. 
As a matter of fact, it is somewhat difficult to use a single verb in the expression of a whole heuristic rule, because it can limit the spectrum of interpretation for design engineers.

In this sense, a significant contribution of the present study deals with the determination of semantic completeness of the heuristic rules. This means that, with the purpose of creating generality for each of the actions encompassed by the rules, the design engineers are provided with an ontology of verbs that are used in the third stage of the heuristic rule selection process. These verbs describe the possible specific actions to be taken on a particular redesign situation, and have been defined by analysing the different design methods detailed before.

The possible actions are grouped into five major categories, and synonyms and verbs that execute similar actions are contained in said categories. This grouping can be seen in Table 2

Table 2 Action synonyms

\begin{tabular}{|c|c|c|c|c|}
\hline REDESIGN & $\begin{array}{l}\text { ELIMI- } \\
\text { NATE }\end{array}$ & MODIFY & $\begin{array}{l}\text { COORDI- } \\
\text { NATE }\end{array}$ & ADD \\
\hline $\begin{array}{l}\text { Aggregate } \\
\text { Consolidate } \\
\text { Build } \\
\text { Superimpose } \\
\text { Couple } \\
\text { Impose } \\
\text { Integrate }\end{array}$ & $\begin{array}{l}\text { Cut } \\
\text { Chop } \\
\text { Destroy } \\
\text { Dissipate } \\
\text { Divide } \\
\text { Remove } \\
\text { Reduce } \\
\text { Separate } \\
\text { Simplify }\end{array}$ & $\begin{array}{l}\text { Associate } \\
\text { Change } \\
\text { Displace } \\
\text { Develop } \\
\text { Divide } \\
\text { Evolve } \\
\text { Exaggerate } \\
\text { Fractionate } \\
\text { Group } \\
\text { Immobilize } \\
\text { Manipulate } \\
\text { Replace } \\
\text { Segment } \\
\text { Standardize } \\
\text { Substitute } \\
\text { Transfer } \\
\text { Transform }\end{array}$ & $\begin{array}{l}\text { Adapt } \\
\text { Adjust } \\
\text { Compensate } \\
\text { Connect } \\
\text { Control } \\
\text { Distinguish } \\
\text { Execute } \\
\text { Integrate } \\
\text { Link } \\
\text { Measure } \\
\text { Realize } \\
\text { Transmit }\end{array}$ & $\begin{array}{l}\text { Aggregate } \\
\text { Associate } \\
\text { Augment } \\
\text { Combine } \\
\text { Build } \\
\text { Create } \\
\text { Develop } \\
\text { Provide } \\
\text { Group } \\
\text { Impose } \\
\text { Integrate } \\
\text { Introduce }\end{array}$ \\
\hline
\end{tabular}

The goal is, on one hand, to aid design engineers in the process of characterizing the specific actions that the redesign demands by providing possibilities for the determination of the most adequate action to be performed on the problem in particular, and suggest possible solution alternatives to be implemented in the process. On the other hand, the purpose is to simplify the interaction between the design engineer and the tool, and still provide valuable output for the creative process. This research aims to set, therefore, a systematic approach for the selection of the proposed heuristic branches in an accurate manner

The actions related to the generation, transmission, interaction or the system, take place on the components. Therefore a number of alternatives of heuristic rules are proposed for the performance of specific actions on the components. (See Figure 3)

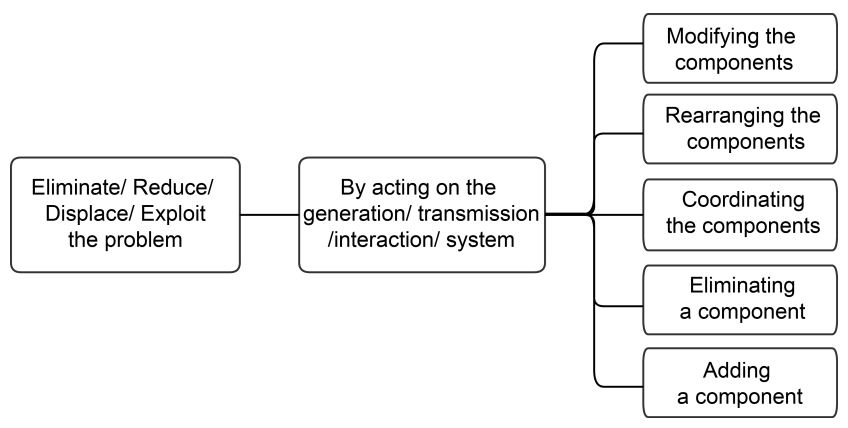

Fig. 3 Actions on the generation, transmission, interaction or the system

In regard to the actions linked to the flow, the particular heuristic rules have been identified from the innovation principles and the standard solutions. The main characteristic of these particular actions is that by acting on the flow or flows that transit between S1 and S2, the design engineer is indirectly acting on the effects generated on the system S2.

In this sense, it is possible to either change the nature of the flow or to act on said flow without changing its nature by modifying the state variables or by superposing a previous action in order to eliminate or compensate the undesired effects. (See Figure 4)

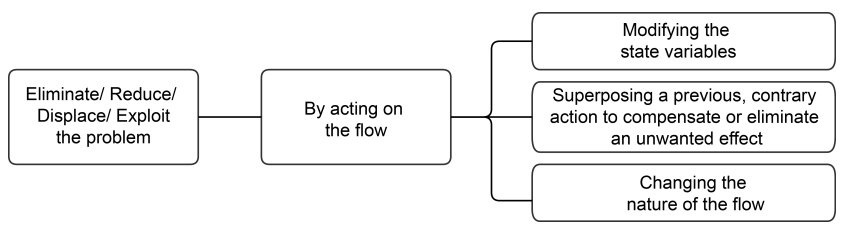

Fig. 4 Actions on the flow

The utilization of heuristics is then performed by choosing the possible alternatives following the three stages previously proposed. Afterwards, by following the selected level of resolution within the spectrum of the heuristics tree, it is possible to escalate in an increasingly precise manner through the diverse levels of the heuristic tree structure. (See Figure 5)

Depending on the objective of the design activity and the dynamism of the group involved in the implementation of the heuristics, the last levels of the structure can be useful or not. Thus, having identified the particular situation of the design activity being developed (whether the effect is desired, insufficient or undesired), it is possible to evaluate the different levels of the heuristic tree, and therefore build up a specific expression that describes a punctual, increasingly specific approach to attack the design problem.

A successive set of choices is then made by the user of the heuristic tree. The task at hand for the design engineer is consequently to interpret the resulting sentence within its 


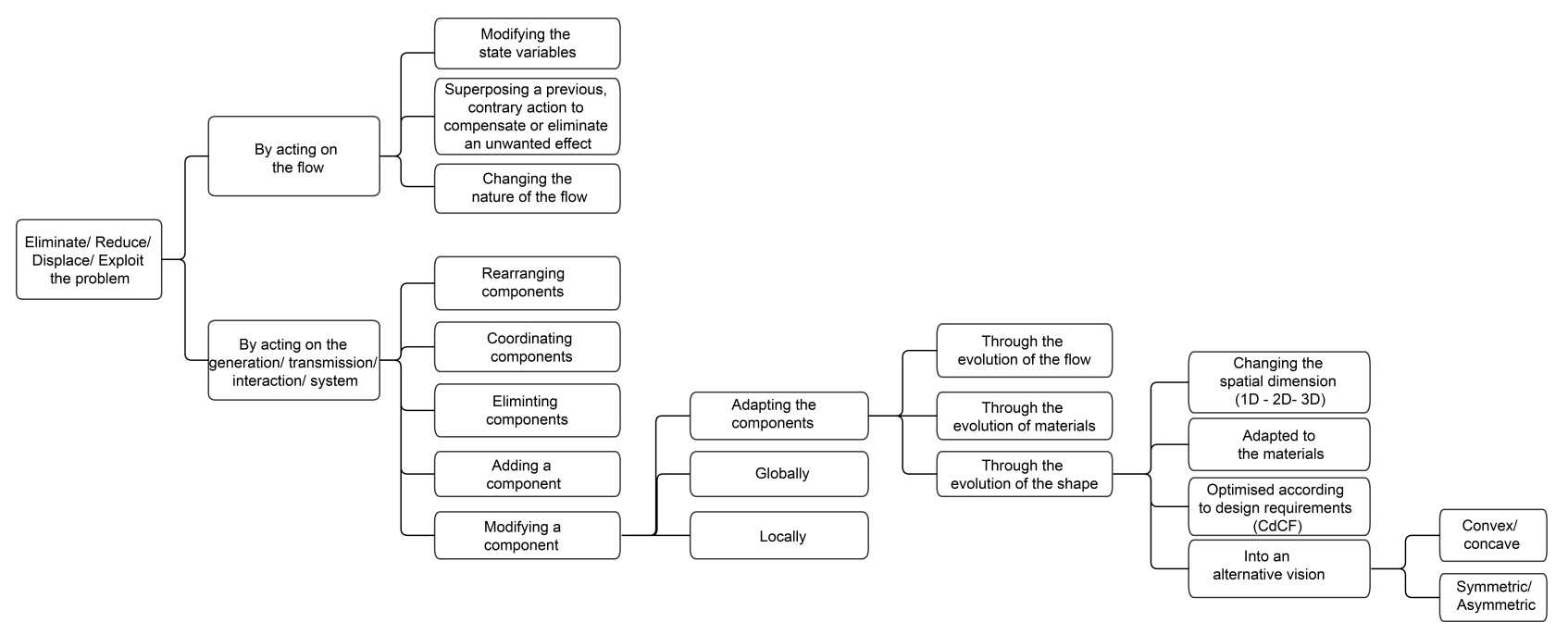

Fig. 5 Representation of a branch of heuristic rules

context of implementation, with the purpose of arriving to actual design solutions.

It is evident that with a heuristic approach it is possible to quickly propose guidelines for reflection to the group of design engineers involved in the development of a solution. Of course, the effectiveness of such implementation depends largely on the correct execution of the Cause-Effect analysis, based upon the procedure for functional and physical analysis presented in this research.

The different branches of the heuristics tree have been evaluated with the aid of diverse examples [17]. These examples have been derived from the analysis of patents and the study of an existing system, in this particular case, a ring support for high pressure turbines, performed for the company Turboméca (Safran Group).

For confidentiality reasons, it is not possible to give detail regarding the evaluation of the heuristics. However, the conclusions of this study show that the different heuristics that have been constructed are coherent with the evolution of techniques and technologies used in the industrial sector of turbomachinery.

A redundancy of the heuristics has also appeared during this study, meaning that many similar solutions have appeared through different paths. This fact, far from being a problem, is an indication of the robustness of the method and different users might find the same solutions while following different thought processes.

In conclusion, this approach enables design engineers to have an exhaustive view of the different possible attack angles for a given design problem. Furthermore, the approach makes it possible to classify the existing solutions of the market and perceive the directions from which a radical innovation might come.

It is important to note that, due to the systematic nature of the approach, one of its key advantages is that the func- tional principles explored in the heuristic tree can be of use for a vast range of design issues.

Once the design engineer has a full perspective on the strategies provided by a particular heuristic rule, a brainstorming process can be carried out, towards the generation of ideas for the problem under question. In this sense, the heuristic rule helps the design engineer to define the desired action to be taken over a particular problem, the area where said action will take place, and the solution strategy itself. The decision making process that conducts the design engineer through the hierarchy will be further described in Section 4.1.3.

For the analysis, the methodology was supported with the development of a tool that consolidates both the heuristic rules and application examples from different fields (e.g., engineering, industrial design and biomimicry) that facilitate the comprehension of the functional principle behind it. The goal is to help design engineers understand how the different solution principles can be integrated into their creative process.

Further detailing of this tool will be given in Section 4 .

\section{Methodology}

The proposed methodology covers two areas of the implementation of heuristics in design. First, it aims to offer a problem solving approach that helps design engineers to specify design tasks more effectively, by resorting to existing knowledge in a structured manner. Second, it provides an approach for the capitalization of emerging knowledge within organizations, with the purpose of contributing to the consolidation of said knowledge derived from design processes, and making it available for future situations. 


\subsection{Use of heuristic rules}

The methodology presented here is based upon the TRIZ approach [2], but it provides additional tools for the structuring and evaluation of the resulting solutions. The procedure comprises three successive stages, as shown in Figure 6.

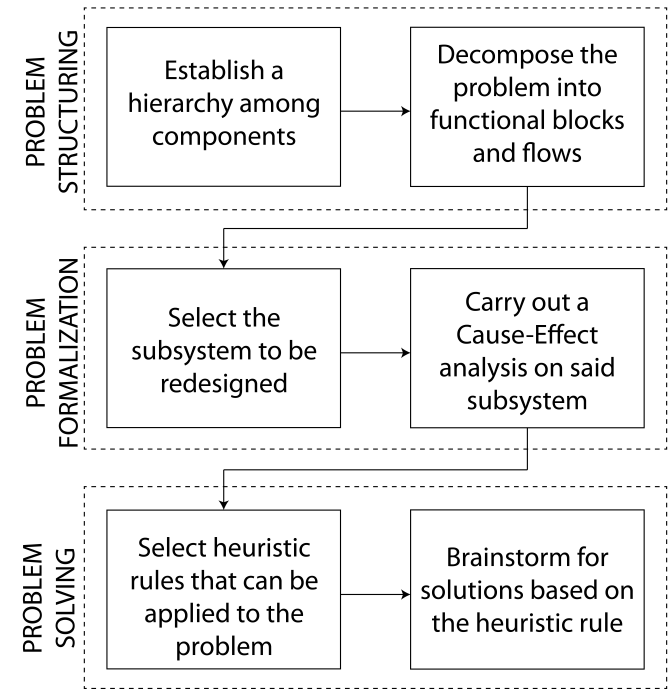

Fig. 6 Methodology overview

\subsubsection{Problem structuring}

The first step towards the resolution of the design problem requires the design engineer to fully understand the nature of the problem itself. For this purpose, the first requirement is the development of a functional decomposition of the overall system into functional blocks and flows. This will enable the design engineer to have a visual representation of the design situation. For the functional disaggregation process, the methodology initially defines the utilization of a Technical Organization Chart (TOC). In order to develop the tool, the design engineer must describe the product at three main levels [20]:

- Products and components

- External environments

- Interactions within the product and with external factors that incise in the product.

Once these elements have been identified, the components must be arranged into a hierarchy.

Afterwards, the design engineer can determine the conflicting components, and select the level at which the problem will be attacked, starting from the global system and descending to component or sub-component levels. At this point, the next step is the determination of functional blocks, which involves zooming into the selected level and describing the interactions within a subsystem.

The determination of functional flows is of crucial importance for the subsequent work. The Technical Organization Chart will help classify the flows according to their characteristics (e.g., matter, energy or signals) and identify their provenance.

An accurate configuration of a TOC depends largely on the expertise and ability of the design engineer or design team. In this sense, it is often easy to spot where the system presents the most significant problems, and therefore where to focus the redesign efforts. But at the same time, the lack of experience or practice in the development of this particular tool can lead the design engineer to obviate or miss connections or disaggregation possibilities within the system. This would eventually mean that one could miss a few problematic elements of the system, or the points where the redesign could have the most meaningful impact.

Therefore, when the problems do not show up immediately, it can be helpful to count with a methodological aid for design engineers to envision the actual possibilities of configurations and interactions between subsystems and components.

For this purpose, the research has formalized an approach that helps design engineers to quantify all the possible interactions within a system, in order to provide the design engineer a tool for the proper identification of the interactions that can pose problems in the product. The approach operates as follows:

If we consider all the possible interactions between components in a TOC, there will be a $k$ number of combinations of elements selected from a domain of $n$ elements. This means that $k \geq 2$ and $k \leq n$. Given that in this particular case it is of interest of the design engineer to understand the interaction between two components, regardless of the level at which the elements are located in the systemic structure, $k=2$.

Having a finite set of elements $\mathbb{E}$, the set of combinations of $k$ elements is noted by $C_{k}^{n}$ and it can be calculated with the following equation:

$C_{k}^{n}=\frac{A_{k}^{n}}{k !}=\frac{n !}{k !(n-k) !}$

where $\frac{A_{k}^{n}}{k !}$ is the number of $k$ possible arrangements of $\mathbb{E}$.

At this point, however, the actual number of interactions remains uncertain, given that the amount of flows that connect two particular subsystem has not yet been determined.

In this sense, we can determine every possibility of interaction as $I_{k_{j}}$, granted that the interaction between components $s_{k}$ and $s_{j}$ exists. $I_{k_{j}}$ represents, therefore, the set of 
flows that connect both components, independently of their nature.

No further detailing of the flows is required at this point, however, given that this subject will be tackled in the following step of the methodology.

This mathematical approach will, in the end, deliver a number of all the possible combinations between two elements, these being components, systems or external factors.

Having established all the possible interactions among components, what follows is the determination of the specific interactions that pose significant problems in a particular system. For this purpose, an evaluation process must be carried out, scoring the relevant interactions and determining which has the largest impact and consequently demands a redesign action. At this point, the evaluation does not fully detail the functional characteristics of the interaction, but rather qualifies the visible effects of it.

For the scoring process we provide an evaluation scale based upon the identification of a number of relevant aspects that will serve design engineers to decide where to focus the redesign efforts. These elements are:

- A classification of the generated effects between two elements, based upon the tool MAL'IN [18]

- An evaluation of the costs associated with taking action over the identified problems.

- An analysis of the level at which the redesign action takes place within the Technical Organization Chart

Table 3 Interaction rating

\begin{tabular}{llll}
\hline Criteria & Weight & Scale & Value \\
\hline \multirow{2}{*}{ Interaction Effects } & w1 & $\begin{array}{l}\text { No effect/ Positive } \\
\text { effect produced } \\
\text { Positive effect } \\
\text { insufficient }\end{array}$ & 0 \\
& & $\begin{array}{l}\text { Positive effect not } \\
\text { produced }\end{array}$ & 2 \\
& & Undesired effect & 3 \\
& & produced & \\
& & No cost & \\
& & Low cost & 0 \\
Cost of Intervention & w2 & Mid cost & 1 \\
& & High cost & 2 \\
& & Subcomponent & 3 \\
\hline \multirow{2}{*}{ Location Level } & w3 & Component & 0 \\
& & Subsystem & 2 \\
& & System & 3 \\
\hline
\end{tabular}

Evaluation of interaction effects: The scale proposed in Table 3 gives the lower value to the interactions that do not affect negatively the system's behaviour, and an increasingly higher value to the interactions which generate the most negative impact in the system.
Of course, it is clear that not all the combinations obtained from the previous operation are meaningful, in the sense that there might be no actual interaction between a set of particular elements. In such case, reasonably, the value is 0 . In other cases, the interaction between components produces effects that are intended or desired; in other words, these interactions occur according to the design specifications. In this case, since the interaction between both components causes no detriment to the system, the value is also 0 .

In cases where the intended or desired effect of an interaction actually occurs, but does not fulfil the requirements originally set by the design specs, the interaction is rated with a value of 1 .

In cases where a desired effect does not occur at all, meaning that the components' interaction does not produce the action that was expected by design, the score of the interaction is 2 .

And finally, when an effect that has not been foreseen and was not intended in the design appears, causing damage or unwanted impacts in the product, the interaction between these components is rated with a value of 3 .

Evaluation of cost of intervention: The rating of this particular item depends largely on the resources available within the organizations, and the ranges or values assigned to every metric in the scale have to be selected by the team. In this sense, it is obvious to assume that those changes or redesign actions that demand less investment of resources are more likely to be executed within an organization than those that require large amounts of resources. Therefore, the scale assigns 0 to the interventions that represent no costs at all, and 3 to the actions that ask for large quantities of resources.

The following is a brief exploration of some of the type of resources that can be considered for the evaluation of this particular item:

- Economic resources: The amount of capital or cash that the particular redesign action demands

- Human resources: The amount of people required for the execution of the redesign

- Time: The amount of time that the redesign of this particular subsystem demands for its execution

According to the availability of these resources, the company can consequently determine what value corresponds to the identified total.

Evaluation of location level: This item in particular refers to the level of the interaction that can be subject of a redesign action, meaning its position in the Technical Organization Chart. The assumption in this regard is that actions implemented at a lower level of the TOC are generally easier to 
perform and have a lower technical complexity than those taken at higher levels.

In this sense, if the interaction occurs at a sub-component level -or lower, if such is the case-, the value assigned to it is 0 .

If the redesign must take place at a component level, the value to assign is 1 . When the redesign action is located at the level of an interaction that occurs among two subsystems, the corresponding value is 2 . When the redesign efforts must be focused at the level of the overall system, consequently, the value is 3 . And finally, if an interaction involves elements from different levels (for example, a subcomponent and a subsystem), the score corresponds to the element located at the higher level.

The ultimate goal of setting this scoring process is to assign a weighed value to every $k_{j}$ according to the performance of the specific interaction in relation to the set criteria. Therefore, having established among all the possible arrangements of $k$, which of them has a higher coefficient, the selection of the interaction to be redesigned appears clear.

Based upon the previous rating, the coefficient of a particular $k_{j}$ can be calculated as follows:

$c_{k_{j}}=\frac{\left[\left(w_{1} \times I\right)+\left(w_{2} \times C\right)+\left(w_{3} \times L\right)\right]}{3}$

Where $c_{k_{j}}$ is the coefficient of interaction $k_{j}$. I corresponds to the value of the interaction effect, $C$ refers to the value assigned to the cost if intervention, $L$ is the value of the location level, and $w_{1}, w_{2}$ and $w_{3}$ correspond to the weights assigned to each criterion.

According to this,

$\sum_{i=1}^{3} w_{i}=1$

It is important to note that the weighing has to be determined according to the priorities of each organization, and this factor has an impact in the accuracy of the selection of the most relevant interactions for redesigning.

It is also relevant to clarify that both the mathematical calculation of the interactions and the scoring of their impacts can be sorted out quickly and might not be demanded in such an exhaustive manner when the expertise of the design engineer or the resources available point out easily where in the system the problem occurs. However, in cases where the problem does not seem evident, it is recommended to follow this approach, and gain expertise through its implementation.

\subsubsection{Problem formalization}

Having determined, with help of the previous evaluation process, where the main problems occur in the system, the next step is to select where to focus the redesign efforts. As it has been previously stated, it is the system or systems with the higher coefficient the ones that must be rethought towards a better performance.

At this point, the goal is to set a number of ways in which the identified problem or problems can be solved. In consequence with the analysis made in the previous stage, the design engineers must select the interactions between elements to be redesigned —one at a time — and disaggregate them.

The methodology proposes a cause-effect approach, as described in Section 3.1.1, which fundamentally poses that every problem can be disaggregated into the following components:

- A first subsystem (S1), which originates the problem. This element can also be disaggregated into two subcomponents:

- The generation, meaning the element that creates the problem,

- The transmission, which is the element that conducts the effects of the problem to $\mathrm{S} 2$

- A second subsystem (S2), the element that suffers the consequences or effects of the problem

- A functional flow transmitted from S1 to S2

- An interaction flow derived from the existence of contact between $\mathrm{S} 1$ and $\mathrm{S} 2$

This model will help design engineers get deeper insights on how and why the interactions occur between subsystems.

The first element to consider when using this approach is the classification of the flows that connect both entities, S1 and S2. In this sense, it is important to determine whether the system's flows correspond to matter, energy or signals. This discrimination will be helpful for the proper identification of where and why the design issues occur.

The effects caused by the interaction between said flow and the entities that it connects are the origin of most of the problems. Therefore, it is important to understand the impact that the action of the flows will produce. Once the nature of the flows is understood, the next step is to identify the following:

- Where in $\mathrm{S} 1$ is the problematic condition produced?

- How does S1 transmit said condition to S2?

- How do S1 and S2 interact? Do they make direct or indirect contact?

- How does S2 reflect the actions that S1 transmits?

This information will enable the design engineer to construct the Cause-Effect model as depicted in Figure 2, which will give the design engineer an overview on how the source and the receptor of the problematic flows relate to each other. At this point, the next stage is to determine what specific effects are produced in $\mathrm{S} 2$ by the flow coming from $\mathrm{S} 1$-which 
is intrinsically related to the questions posed above, and in particular with the latter- and the induced effects that are derived from them.

The evaluation of the impact of the induced and produced effects will determine the kind of action required for the solution of the problem [19]. This means that the design engineer can choose whether to act on the generation, transmission or interaction of the problem within the system, or in the overall system itself, in order to avoid the occurrence of detrimental effects such as the ones listed in Table 1 . From this point on, the design engineer can relate the situation to the heuristic hierarchy, therefore implementing heuristic rules to solve the problem under question with the purpose of taking action over the identified effect.

\subsubsection{Problem solving}

As it has been previously stated, the present research proposes the incorporation of a set of 78 heuristics arranged in a branched structure, so as to enable the design engineers to explore the different strategies according to the characteristics of the problem. The following is the approach suggested for the utilization of the heuristics:

- Determine the desired kind of action to be taken over the problem: (a) eliminate, (b) reduce, (c) exploit or (d) displace the problem

- Locate the efforts of said action in a particular point of the system, understood from the perspective of a causeeffect model: (a) the flow or (b) the system. If the design engineer chooses to take action over the system, the specific location of the action must also be defined: generation, transmission, interaction, or the overall system itself

- Select, from a range of possible strategies contained in the tree-like structure, what kind of specific action does the design engineer want to implement for the achievement of the set goal. The choice made depends largely on the possibilities of the system itself, the capabilities within the company and the skills of the design engineer.

- A consecutive set of choices will drive the design engineer through the branched structure, all the way to a final, highly specific heuristic strategy presented in the shape of a full sentence, that offers a particular functional principle to be explored and implemented into the creative process. This functional principle is explained by a physical or mechanical concept that describes the operation of the heuristic, in order for design engineers to fully understand the range of possibilities contained in the rule.

In order to provide a user-friendly approach for the understanding of heuristic rules in context, the heuristics tree and the solution principles are presented in the shape of a card that shows examples of applications of the functional principle under question in diverse areas, and details how the principle works in each of the cases.

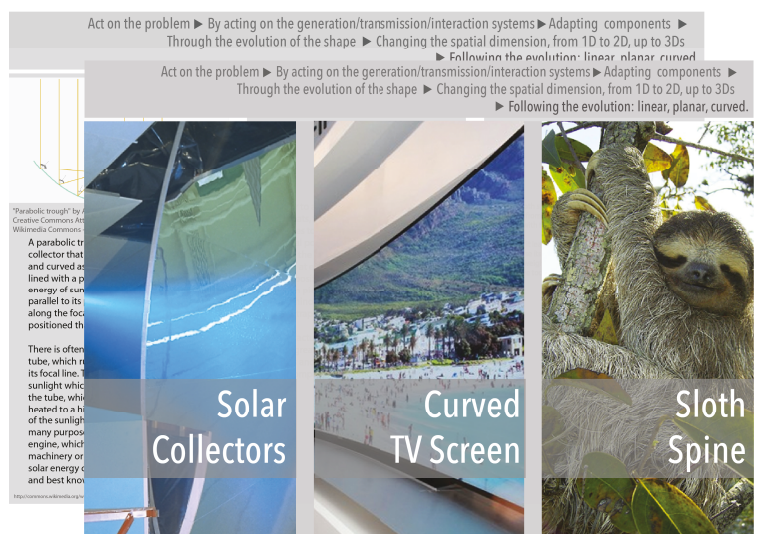

Fig. 7 Heuristic cards example

Each heuristic card contains the whole expression of the heuristic rule under study, in order to help design engineers keep in mind what particular solution they are intending to implement.

Additionally, each card contains three examples of the implementation of said rule, in order to clarify how the functional principle works. The examples, as it has been stated before, come from different areas of knowledge. In general, the three examples are divided as follows:

- An industrial application of the principle

- An example derived from product design and consumer products

- An application of the principle in nature (biomimicry)

The application examples are also associated with a brief description of the principle at work, in most cases both graphically and textually.

In the card shown in Figure 7, for instance, three examples display diverse applications of the same heuristic principle, which in this case is: Acting on the generation, interaction, transmission or system through the adaptation of components through the evolution of the shape, by changing the spatial dimension from $1 D$ to $2 D$ up to $3 D$, following the evolution: linear, planar, curved

The examples shown are:

- A parabolic solar collector

- A curved TV screen

- The spine of a sloth

These examples display, in different ways, the geometrical evolution of a shape from linear or planar to curved. 
Parabolic solar collectors, for instance, make use of a curved shape for the purpose of concentrating sunlight in a focal point, increasing intensity. Curved TV screens use the curved surface to improve the field of vision of the spectator. And finally, sloths tend to maintain a hanging position for long periods of time; therefore, a curved spine helps sloths deal with tension in this upside down position.

In addition, the card contains a brief explanation of a general physical principle behind each example of the heuristic rule. This aims to aid design engineers to identify relevant parameters and a specific, practical action path for the implementation of the solution into their particular context.

In the case of the parabolic solar collector, for instance, the collector concentrates the solar energy on a tubular manifold. The relevant parameters in this case are related to the balance of the tubular manifold, as described in Figure 8

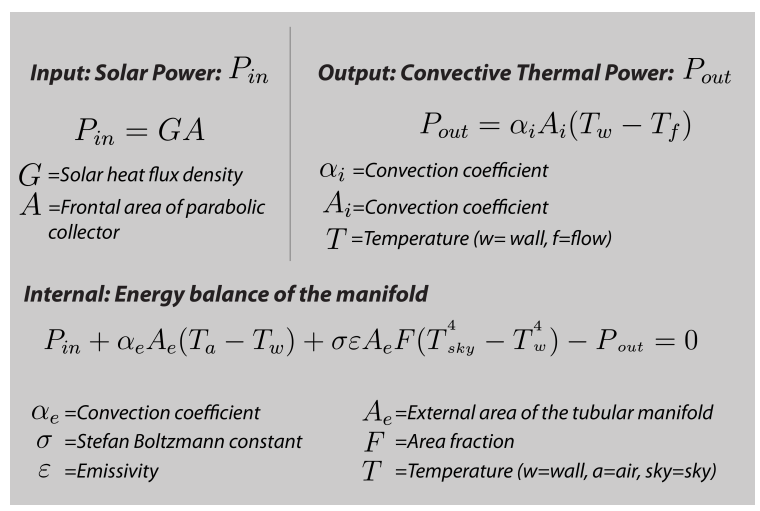

Fig. 8 Resolution: Physical concepts example

Fundamentally, the purpose of integrating the concept of a full heuristic rule aims to simplify and synthesise the work of the heuristics tree into a user-friendly tool.

The ultimate goal is to trigger creative thinking in the design engineer or design team that implements the present methodological approach, by providing them with tools to explore an ensemble of solution strategies applicable to a wide range of design problems.

\subsection{Capitalization of knowledge}

Aside from providing a structured approach towards the usage of heuristic rules, the research also focuses in ensuring that emerging knowledge will be preserved and become tangible for future reuse.

This means that, whenever a design process leads to the creation of new or meaningful knowledge, the organization counts with a method that enables the incorporation to said knowledge to the knowledge base provided by this study. At this point, it is important to note that determining the level of novelty of the generated knowledge is subjective; what matters is the relevance this knowledge has for the organization in particular, and whether preserving it adds any value to the habitual operations of said organization.

The following is the suggested procedure for the capitalization of knowledge.

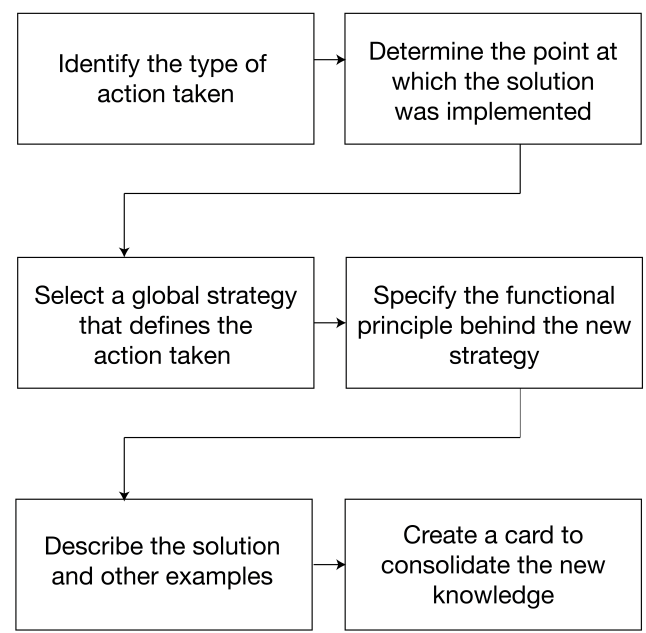

Fig. 9 Knowledge capitalization model

First, it is important to analyze the recently solved design situation under the light of the method proposed above, in order to create a common ground for the desired integration. In this sense, the design engineer must identify what kind of action explains the redesign activity -namely, eliminating, reducing, displacing or exploiting the problem- and where in the redesign process did the action take place, from the perspective of a cause effect model -generation, transmission, interaction or effect of the problem.- This definition will serve to identify where the new knowledge will be located in the arborescence.

The next step is to define which of the global strategies describes best the kind of action taken during the redesign, in order to select a particular branch to accommodate the new rule. The goal is to determine at what level do the existing rules describe the new solution, and how to formulate the remaining sections of the heuristic rule. The definition of a global principle will also be helpful for the understanding and framing of the specific functional principle that describes the strategy, which will enable the completion of the sentence that corresponds to the rule.

Finally, it is important to develop the practical tool that will serve for future processes; in this case, the card. Following the guidelines of the card shown in Figure 7, it is required to describe the present solution in terms of the physical phenomena that define it. It is also suggested to identify other examples of this solution in different domains (e.g., biomimicry and industrial design), which will help to better understand what the solution entails. 


\section{Case study}

\subsection{Validation method}

In order to obtain relevant data for the improvement of the methodology and the tools associated with it, the process has been evaluated in a preliminary case study, where it has been subjected to comparison with a conventional design approach.

The pilot study was carried out with a number of teams of designers and engineers with different backgrounds (mechatronics, industrial design, biomedical engineering, etc.), but similar levels of experience. The subjects were given the same task: to rethink a conventional coffee maker. The purpose was to compare the performance of the teams, taking as a basis the following setup:

- An initial experiment would be carried out with three different teams, who would approach the task using familiar design techniques, and their performance statistics would be taken as a reference or benchmark for further evaluation.

- A second experiment with three additional teams would follow the approach proposed in the present research and implement in their process a set of heuristic rules.

- Each team would perform the task separately, in order to avoid external influence in the process. With the same purpose, each subject could participate in only one experiment.

In the subsequent sections, a brief description of the process followed by the design teams will be described.

\subsubsection{Experiment 1: Benchmark}

The first experiment, as mentioned above, involved the participation of teams that did not follow the methodology proposed by the present research. Instead, they used an unstructured approach that in general consisted of the following steps:

- Detection of issues in the coffee machine through the execution of a brainstorming process

- Functional analysis and component selection

- Product architecture

- Concept generation and evaluation

In most of these cases, the result was a formal redesign that attacked some of the problems spotted in the brainstorming process, but the level of depth of the technical detailing was merely superficial.

\subsubsection{Experiment 2: Heuristic rules}

The teams that participated in this experiment were instructed in the use of heuristic rules in the creative process, and were given a general overview of the proposed methodology. With this input, all of the teams began with the identification of components and external factors that have an incidence in the product, through the development of a Technical Organization Chart, of which Figure 10 is an excerpt from one of the teams. With this visual representation of the product, they were able to spot problematic areas at different levels of the product.

In particular, the design issues that the teams encountered can be classified in three different categories:

- Poor physical interactions among components (adjustment between parts)

- Conflicts in variable management (temperature isolation and control)

- Poor signal management and user interface problems.

Once the main design issues were identified, the team conformed a set of functional blocks , and defined and classified the interactions between the components involved in the problematic situation, as well as the flows that connect said blocks.

At this point, the analysis of the number of possible interactions (Equation 1) was carried out. In the case depicted in Figure 10, for instance, 120 possible interactions resulted from the analysis. However, given the preliminary character of the exercise, the prioritization process did not take into account all the interactions, but only those directly related to the problems spotted in an earlier stage of the process.

In this sense, the teams listed and weighed the interactions according to the methodology proposed in Section 4.1.1. An example of this evaluation is shown in Table 4

Table 4 Interaction evaluation: Example

\begin{tabular}{lllll}
\hline INTERACTION & VAR. & W & RATING & TOTAL \\
\hline \multirow{3}{*}{ Resistor - Container } & I & 0.6 & 1.8 & \\
& L & 0.1 & 0.2 & 0.87 \\
& L & 0.3 & 0.6 & \\
Chassis - Container & I & 0.6 & 1.8 & \\
& L & 0.1 & 0.2 & 0.87 \\
& L & 0.3 & 0.6 & \\
Water - Container & I & 0.6 & 1.2 & \\
& C & 0.1 & 0.1 & 0.63 \\
Input - Output & L & 0.3 & 0.6 & \\
& I & 0.6 & 0.6 & \\
& C & 0.1 & 0.3 & 0.50 \\
Coffee - Water & L & 0.3 & 0.6 & \\
\hline & I & 0.6 & 1.8 & \\
& C & 0.1 & 0.2 & 0.77 \\
\hline
\end{tabular}

According to the evaluation, the higher scoring interactions were later analysed under the perspective of a cause- 


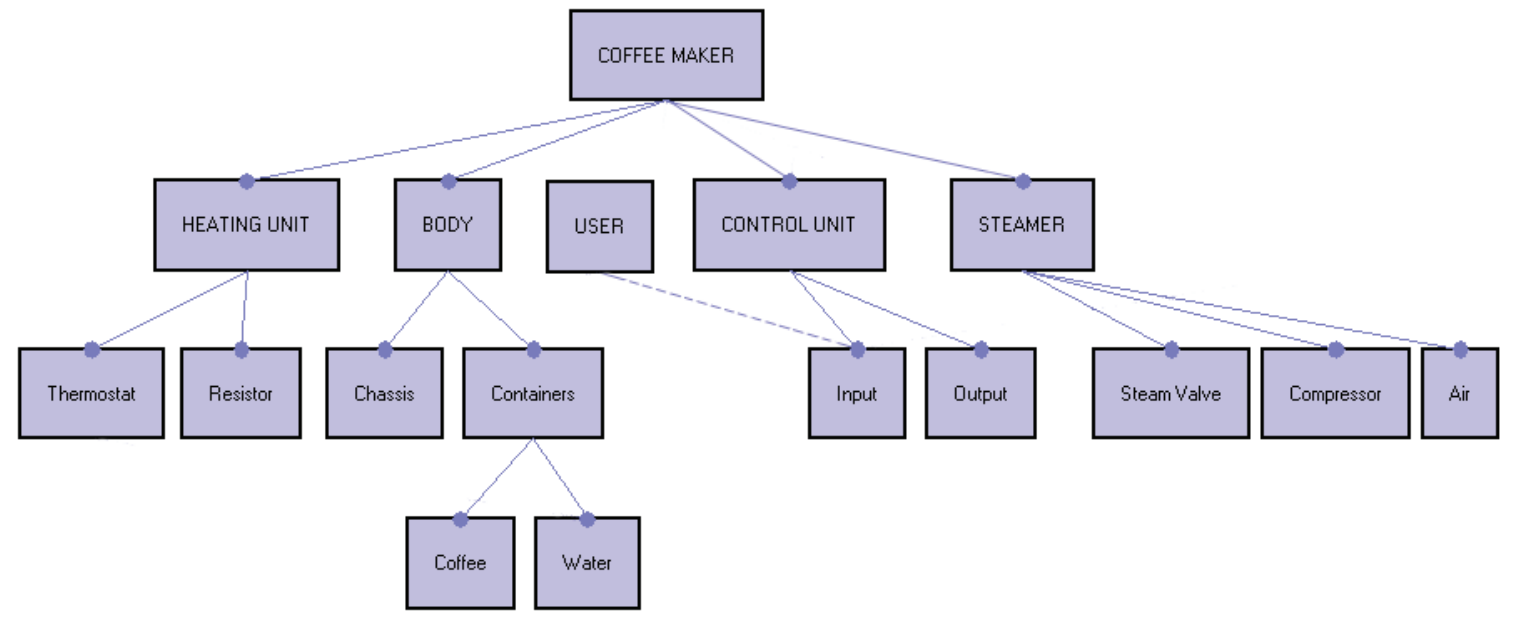

Fig. 10 Technical Organization Chart

effect model, helping the design engineers to define where to locate the redesign effort.

In the case displayed in Figure 11, for instance, it became apparent that one of the main issues was the deficient heat management, caused by a poor isolation of the resistor, which generated deformations in seals and casings.

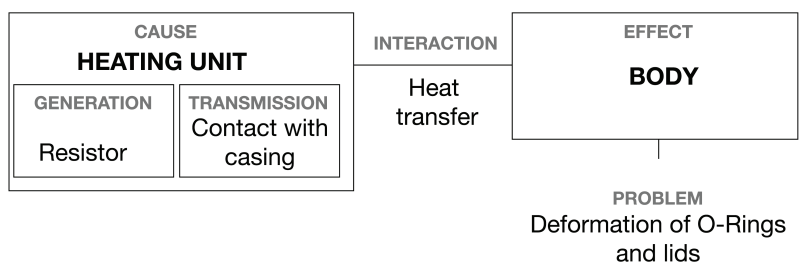

Fig. 11 Cause-Effect model

Once the teams selected whether to act on the generation, transmission, interaction or effect of the selected problems, heuristic rules were implemented. The decision on where to locate the actions enabled the design engineers to approach the heuristics tree-in this case, a shortened version with 9 different branches- Each of the branches conducted to one of 9 cards like the one depicted in Figure 7, each of them detailing a different functional principle. The team studied the tree and the cards, associating them to their particular case through interpretation, and selected those which could be easily related to their problem.

Some of the functional principles identified and selected by the teams in the heuristic cards were:

a. The modification of state variables at a local scale - in this particular case, temperature-

b. The segmentation of a component into layers or the use of multi-materials

c. The evolution of a system through the incorporation of porous media.
Afterwards, the design engineers moved on to the generation of solution alternatives for each of the subsystems, eventually developing concepts as a result of the integration of the redesigned subsystems.

\subsubsection{Redesign Outcomes}

Given that all the participating teams carried out the same redesign task, -namely, take a regular coffee machine and redesign it based upon a product analysis- the differences between the resulting redesigns were easily comparable between each other from a visual perspective.
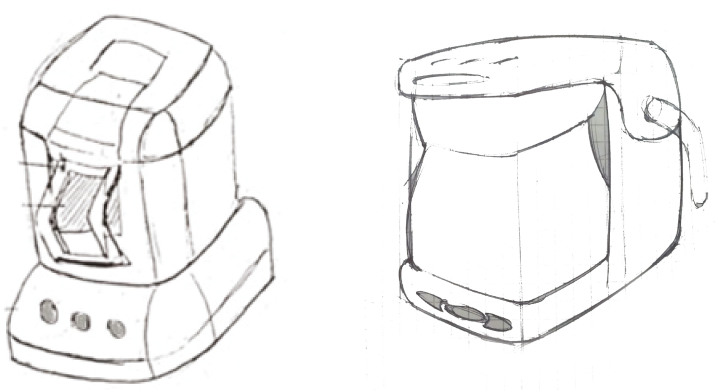

Fig. 12 Redesign outcomes: Benchmark

The design concepts shown in Figure 12 display some of the results obtained by the design teams that used an unstructured approach for the design process. Figure 13 shows results obtained by the design teams that implemented heuristics.

Based upon observation, it is possible to see that the concepts presented by the benchmark teams focuses its redesign mostly on formal aspects and very little functional detailing is given, as it has been mentioned before. Meanwhile, all the concepts presented by the teams that implemented heuris- 


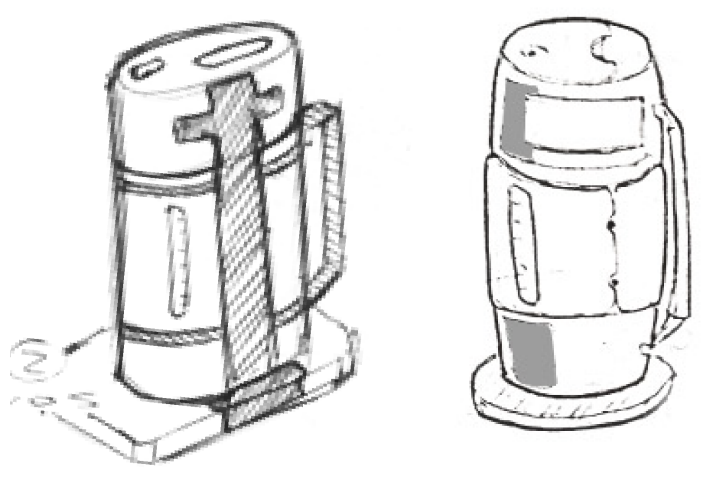

Fig. 13 Redesign outcomes: Heuristics

tics show redesign efforts in diverse subsystems of the product, creating a particular product architecture that ultimately shapes the design. The subsystem approach, which occurred in every case with the implementation of heuristics, can be observed in the annotations and zoom-ins that accompany their designs. An example of the detailing level can be seen in Figure 14.

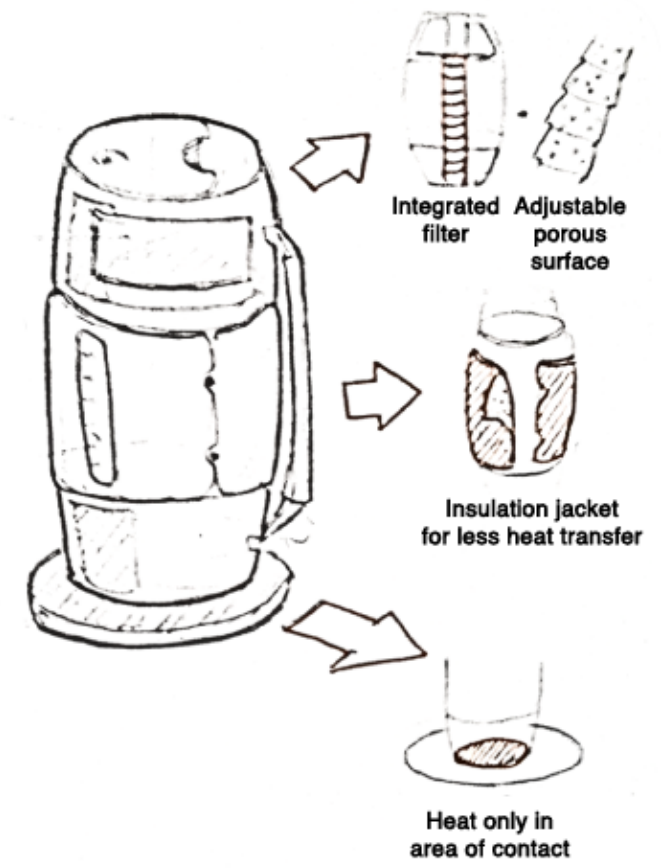

Fig. 14 Redesign outcomes: detail

The design alternatives developed by the teams that implemented heuristics show clearly how the rules were implemented in the process, with the purpose of solving the problems that had been identified in earlier stages.

For instance, in Figure 14 the incorporation of thermal jackets appeals to the heuristic rule that suggests the evolu- tion of the system through the incorporation of layers. Similarly, the transformation of the heating unit through the implementation of induction heaters relates to the heuristic that proposes to modify the state variables of a system at a local scale.

The detailing of the application of specific heuristic rules in the redesign is shown in Table 5, particularly setting the example of one of the teams that used heuristics.

Table 5 Heuristic rules in the redesign: Example

\begin{tabular}{|c|c|c|}
\hline APPLICATION & OBJECTIVE & RULE \\
\hline $\begin{array}{l}\text { Use of induction } \\
\text { heat platform } \\
\text { for fluid heating }\end{array}$ & $\begin{array}{l}\text { Improve } \\
\text { temperature } \\
\text { control and } \\
\text { avoid heat } \\
\text { transmission to } \\
\text { other elements }\end{array}$ & $\begin{array}{l}\text { Act on the problem - By acting } \\
\text { on the flow - Through the } \\
\text { modification of state variables } \\
\text { - Locally }\end{array}$ \\
\hline $\begin{array}{l}\text { Incorporation of } \\
\text { thermal jacket } \\
\text { for temperature } \\
\text { isolation }\end{array}$ & $\begin{array}{l}\text { Prevent fluid } \\
\text { heat loss after } \\
\text { power off }\end{array}$ & $\begin{array}{l}\text { Act on the problem - By acting } \\
\text { on the generation/ } \\
\text { transmission/ interaction/ } \\
\text { system -Through the } \\
\text { modification of components - } \\
\text { Globally - Through the } \\
\text { structural segmentation of } \\
\text { components - By layers }\end{array}$ \\
\hline $\begin{array}{l}\text { Design of } \\
\text { porous } \\
\text { permanent filter }\end{array}$ & $\begin{array}{l}\text { Eliminate } \\
\text { removable } \\
\text { components } \\
\text { that deform } \\
\text { with heat }\end{array}$ & $\begin{array}{l}\text { Act on the problem - By acting } \\
\text { on the generation/ } \\
\text { transmission/ interaction/ } \\
\text { system - Through the } \\
\text { modification of components - } \\
\text { Through adaptation of } \\
\text { components - Through } \\
\text { evolution of materials - } \\
\text { Towards porous materials or } \\
\text { multimaterials }\end{array}$ \\
\hline
\end{tabular}

As it can be seen, the outcome reached by the teams that implemented heuristics, and the case shown in Table 5 in particular, displays the usefulness of heuristic rules in the redesign of diverse subsystems.

The comparison and evaluation of the redesigns will be further detailed in the following section.

\subsection{Results}

As it was shown before, the design approach of both subgroups was significantly different. However, an analytic process helped the researchers identify how the key dissimilarities reflect in the final results, and how can these differences be related to the implementation of heuristic rules. Furthermore, it helped in spotting possible benefits and disadvantages of said implementation.

The first and more evident difference is related to time management throughout the process.

The results, as seen in Figure 15, show that the teams that approached their task with the implementation of heuristics 


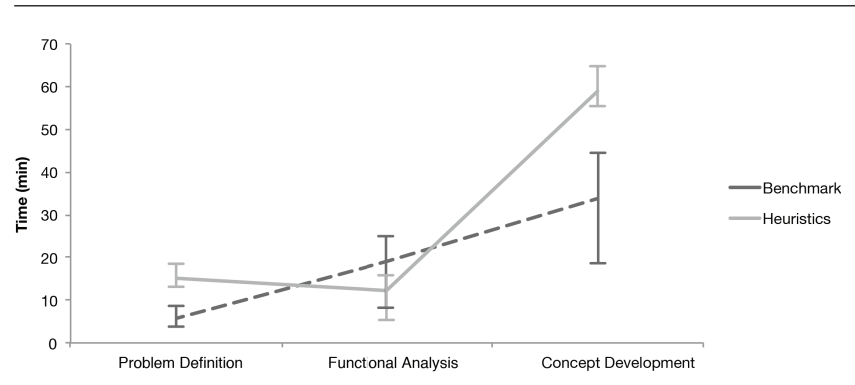

Fig. 15 Results: Time performance

spent, on average, a very similar time in structuring the design problem -meaning, Problem Definition and Functional Analysis- with teams that implementing heuristics spending on average $8 \%$ more time; however, the heuristics teams spent $36.99 \%$ less time in Functional Analysis itself, in comparison to the benchmark team. It is also worth noting that the benchmark teams spent $42.95 \%$ less time in the conceptualization stage than the average of the other teams.

The statistical analysis goes in line with the results shown in Section 5.1.3, where it becomes evident that the level of detailing reached by the teams that implemented heuristics was significantly higher than that of the benchmark team, which can also be seen in Table 6 .

As it was mentioned before, the design approach of both teams was significantly different; while benchmark teams in general made a strict differentiation between functional and formal aspects of the design, the teams that used heuristics deepened in the functional aspects, which in turn determined the appearance of the product. This is reflected in the amount of concepts generated; while benchmark teams developed a larger number of formal concepts, the teams with heuristics generated less concepts, but each of them with a larger number of subsystems redesigned. This, of course, is derived from the approach by subsystems that the methodology proposes, which helps design engineers get a better overview of the design problem from a functional perspective.

Table 6 Results

\begin{tabular}{llll|lll}
\hline \multirow{2}{*}{ VARIABLE } & \multicolumn{3}{c}{ BENCHMARK } & \multicolumn{3}{c}{ HEURISTICS } \\
\cline { 2 - 7 } & A & B & C & D & E & F \\
\hline $\begin{array}{l}\text { Total time (min) } \\
\text { No. of problems }\end{array}$ & 87 & 30 & 68 & 89 & 85 & 83 \\
$\begin{array}{l}\text { identified } \\
\begin{array}{l}\text { No. of functional } \\
\text { blocks identified }\end{array}\end{array}$ & 11 & 6 & 9 & 9 & 10 & 9 \\
$\begin{array}{l}\text { No. of product } \\
\text { architectures } \\
\text { developed }\end{array}$ & 1 & 1 & 2 & 2 & 1 & 1 \\
$\begin{array}{l}\text { No. of concepts } \\
\text { generated }\end{array}$ & 4 & 2 & 2 & $1(6)$ & $2(5)$ & $1(3)$ \\
\hline
\end{tabular}

In general, the study suggests that, when exposed to heuristic tools, design teams can reach more detailed functional concepts, thus opening the possibility of saving time and effort in the subsequent stages of the process because fewer efforts are required in adjusting functional and formal solutions to a same design problem.

\subsection{Discussion}

It is important to note that the contribution of the present work is focused on providing the design engineer with a set of possible solution principles for diverse design problems. This implies that, in order to fully exploit the potential of the tools explored here, the design engineer must approach the methodology with an existing problem at hand, in order to be able to identify the action to be taken over said problem.

This means that the tool will not provide equally useful results for the generation of initial concepts where no previous reference exists, given that at this point of the process, in most cases, design engineers do not have a tangible problem to attack through heuristic rules.

\section{Conclusions and future work}

Based upon the ample multidisciplinarity and diversity of backgrounds of the participants in the validation process, and judging by their response to the implementation of the heuristic approach to design tasks, it is possible to say that the scope and reach of the tool is remarkably wide. This means that both the methodological approach and the support tools developed during this research can be of use for design practitioners regardless of their specific backgrounds, thanks to the generality and ease of understanding of the heuristic rules provided, and the broad spectrum of applications shown in the tools.

During the study a particular advantage of the implementation of heuristics became apparent: lateral thinking processes started happening in the ideation stages, meaning that design engineers did not limit themselves to thinking within the functional domain of their design problem; most of the ideas came from functional applications in completely different domains such as architecture and biology. Furthermore design engineers did not limit themselves to the generation of concepts within the functional spectrum of the proposed rules. Instead, the rules often triggered ideas not directly related to the functional principles explained, but somehow connected to them. This opened the opportunity for more diverse concepts.

Furthermore, the level of complexity and detailing of the concepts reached by the participants during the brief design exercises was clearly higher when a heuristic approach was 
implemented than when the design engineers followed a traditional, often loosely structured approach. This can give an idea of how the overall design process can be sped up in future stages thanks to the greater detailing level obtained in initial stages.

However, the statistical validity of the present study is limited, and therefore it is recommended to carry on with the validation process until a statistical relevance for the research is reached.

The current validation process has covered the scope of a design task from the problem definition to the general architectural structuring of a solution. However, it is important to assess what kind of input can be provided to the rest of the process by the implementation of heuristics into conceptualization, detailed design and materialization. Furthermore, it is crucial to evaluate the overall design process from conception to materialization, in order to fully understand the effects of heuristics in design.

It is also necessary to approach the dilemma design engineers face when having to decide which branch to follow towards the resolution of the design problem. In this sense, it is important to evaluate how to guide design engineers effectively through the decision-making process associated with the selection of particular heuristic rules, and provide them with the appropriate rules for the specific problems being explored.

The current research has been carried out within an academic environment, giving positive results. However, the applicability of the proposed method in industrial environments is yet to be determined. Nevertheless, the fact that the formulation of the heuristics contained in this study has been largely based on work carried out in collaboration with industries should serve as a preliminary indicator of its validity. In this sense, it is interesting to provide information and feedback related to the usage of the tool in industrial applications.

Furthermore, the implementation of a software development for the exploration of the heuristics tree has proven to be of interest during academic exercises, taking into account that the research has demonstrated that heuristics can make the design activity more effective. In this sense, automating the interaction process between the design engineer and the heuristic rules can help speed up the process of selecting and interpreting heuristic rules, thus minimizing time in the overall design process. Plus, its impact can be maximized if prepared for commercial applications. Therefore, future work will be dedicated to the strengthening of a virtual support tool for the implementation of heuristics into the design process.

Acknowledgements The authors would like to thank the Research Department of Universidad EAFIT, and in particular the Research Group in Design Engineering for their participation in this research. The au- thors would also like to thank ParisTech, and in particular the Arts et Metiers' I2M Lab for their valuable contribution to the development of the present work.

\section{References}

1. Altshuller, G., Shulyak, L., Rodman, S., Fedoseev, U.: 40 principles: TRIZ keys to innovation, vol. 1. Technical Innovation Center, Inc. (1998)

2. Altshuller, G.S.: The history of ariz development. Journal of TRIZ 3 (1986)

3. Beheshti, R.: Design decisions and uncertainty. Design Studies 14(1), 85-95 (1993)

4. Ceruti, A., Caligiana, G., Persiani, F.: Comparative evaluation of different optimization methodologies for the design of uavs having shape obtained by hot wire cutting techniques. International Journal on Interactive Design and Manufacturing (IJIDeM) 7(2), 63-78 (2013)

5. Daly, S.R., Yilmaz, S., Christian, J.L., Seifert, C.M., Gonzalez, R.: Design heuristics in engineering concept generation. Journal of Engineering Education 101(4), 601-629 (2012)

6. Eberle, R.F.: Developing imagination through scamper*. The Journal of Creative Behavior 6(3), 199-203 (1972)

7. Favi, C., Germani, M.: A method to optimize assemblability of industrial product in early design phase: from product architecture to assembly sequence. International Journal on Interactive Design and Manufacturing (IJIDeM) 6(3), 155-169 (2012)

8. Fischer, X., Coutellier, D.: The interaction: a new way of designing. In: Research in Interactive Design, pp. 1-15. Springer Paris (2006)

9. Fischer, X., Nadeau, J.P.: Interactive design: Then and now. In: Research in Interactive Design Vol. 3, pp. 1-5. Springer Paris (2011)

10. Gordon, W.J.: Synectics: The development of creative capacity. (1961)

11. Householder, A.S.: Monte Carlo Method. US Government Printing Office (1951)

12. Kennedy, J., Eberhart, R., et al.: Particle swarm optimization. In: Proceedings of IEEE international conference on neural networks, vol. 4, pp. 1942-1948. Perth, Australia (1995)

13. Kolodner, J.: Case-based reasoning. 1993. Morgan Kaufmann, San Mateo, CA (1995)

14. Kolodner, J.L.: An introduction to case-based reasoning. Artificial Intelligence Review 6(1), 3-34 (1992)

15. Koza, J.R.: Genetic programming as a means for programming computers by natural selection. Statistics and Computing 4(2), 87-112 (1994)

16. Merriam-Webster:.: Heuristic. Encyclopaedia Britannica (2014)

17. Morillon, T.: Mise en place de standards technologiques pour la maîtrise des pertes de rendement en face externe de veine de turbine haute pression. PhD (2009)

18. Nadeau J.P. Pailhes P., O.P.: Mal'in software (2004)

19. Pailhès, J., Sallaou, M., Nadeau, J.P.: Knowledge base formulation for aided design tool. In: Advances in Integrated Design and Manufacturing in Mechanical Engineering II, pp. 231-243. Springer (2007)

20. Pailhès, J., Sallaou, M., Nadeau, J.P., Fadel, G.M.: Energy based functional decomposition in preliminary design. Journal of Mechanical Design 133(5), 051,011 (2011)

21. Polovinkin, A.: Theory of new technique design: Laws of technical systems and their applications (1991)

22. Roozenburg, N.F., Eekels, J.: Product design: fundamentals and methods, vol. 2. Wiley Chichester (1995)

23. Simon, H.A.: The sciences of the artificial. MIT press (1996) 
24. Smith, P.G., Reinertsen, D.G.: Developing products in half the time, (advanced praise for developing products in half the time: New rules, new tools) (1998)

25. Soegaard, M.: Heuristics and heuristic evaluation (2004)

26. Stone, R.B., Wood, K.L., Crawford, R.H.: A heuristic method for identifying modules for product architectures. Design studies 21(1), 5-31 (2000)

27. Tessari, R.K., De Carvalho, M.A.: Compilation of heuristics for inventive problem solving

28. Yilmaz, S., Seifert, C.M.: Creativity through design heuristics: A case study of expert product design. Design Studies 32(4), 384415 (2011) 